\title{
Wallflowers: Experimental Evidence of an Aversion to Standing Out
}

\author{
Daniel Jones ${ }^{\mathrm{a}}$ \\ Sera Linardi ${ }^{\mathrm{b}}$ \\ University of Pittsburgh
}

\begin{abstract}
An extensive literature on reputation signaling in prosocial settings has focused on an intrinsic desire for positive reputation. In our paper, we provide experimental evidence that some individuals are averse to both positive and negative reputation and will therefore respond to visibility by signaling that they are an "average altruism type" relative to their audience. We formalize our hypotheses about "wallflower" behavior in a theoretical model. Our experimental results show that instead of uniformly increasing contributions, visibility draws contributions towards the middle of others' contributions. As a result, visibility is associated with higher levels of giving only when in scenarios where others are giving a large amount. We also observe heterogeneity in reputation concerns: wallflower behavior is particularly strong for women and can be observed in several different settings.
\end{abstract}

aJones: Department of Economics, University of Pittsburgh, Pittsburgh, PA 15260, USA. Email: dbj3@pitt.edu. ${ }^{\mathbf{b}}$ Corresponding author. Linardi: Graduate School of Public and International Affairs and Department of Economics, University of Pittsburgh, Pittsburgh, PA 15260, USA. Email: linardi@pitt.edu Phone: (412) 648-7650 Fax: (412) $648-7641$

We thank Lise Vesterlund for very helpful discussions. We also thank Jim Andreoni, Erin Krupka, Michael LeGower, Maria Patricia Recalde, and participants at the Pittsburgh Experimental Brownbag, the ESA 2011 meeting (Tuscon), the 2011 ARNOVA meeting (Toronto), the 2012 Workshop on Social Dimension of Organizations, the 2013 Social Dilemma Workshop (Caltech), the CAGE/CMPO Conference on Generosity and Wellbeing (Warwick), as well as seminar participants at Universitat Bonn, IUPUI, University of Michigan (STIET), and University of Massachusets-Amherst for helpful comments. We thank GSPIA for their financial support (SL) and Kate Morris for her careful reading of the draft. 


\section{Introduction}

How does visibility impact prosocial behavior? If the desire to appear altruistic (or avoid appearing selfish) is an important motivator for prosocial behavior (Becker, 1974; Benabou and Tirole, 2006), then public recognition should induce individuals to contribute more to social causes and public goods. Indeed, the experimental literature documents that the relationship between visibility and prosocial behavior is often positive. However, a number of visibility treatments have produced null or negative results (Fehr and Gachter (1999), Soetevent (2005), Dufwenberg and Muren (2006), Noussair and Tucker (2007), Alpizar et al. (2008), and Reinstein and Riener (2012)), suggesting that the impact of public recognition may be more complex than commonly thought. ${ }^{1}$

There are hints in recent work that some individuals shy away from standing out as particularly selfish or generous. Peacey and Sanders (2012) find that donations that are particularly large or small are more likely to be made anonymously than moderately sized ones. Shi (2011) finds that public recognition is the only incentive for blood donations that decreased survey respondents' reported willingness to participate. Engel's (2011) meta-study of dictator games concludes that dictators are less likely to keep everything for themselves when they are identified, but they are also less likely to give more than half of the pie.

In this paper, we propose that some individuals are wallflowers who are averse to standing out in positive and negative ways. A reputation as an altruist may not be beneficial if there is a possibility of being alienated for being "too good", being suspected of being an image-motivated person, or attracting other such unwanted attention. ${ }^{2}{ }^{3}$ While an individual of the canonical honor-seeking type benefits from

\footnotetext{
${ }^{1}$ Visibility increases contribution in public goods games in Bohnet and Frey (1999), Andreoni and Petrie (2004), and Rege and Telle (2004). See Bekkers \& Wiepking (2011) for review from both economics and psychology, which also suggests a generally positive impact of recognition. Visibility does not increase contributions if contributors have not meet and interact beforehand (Gachter and Fehr, 1999), funds are intended for an internal cause (Soetevent, 2005), donors have not received a small gift (Alpizar et al., 2008), and when giving is simultaneous (Reinstein and Reiner, 2012). Visibility decreases giving in Dufwenberg and Muren's (2006) dictator game and Noussair and Tucker's (2007) repeated public goods game.

${ }^{2}$ Here reputation refers to intrinsic reputation concerns (as in Benabou \& Tirole, 2006) as opposed to strategic reputation concerns which only arise in repeated games and have been shown to sustain cooperation in repeated games (Wedekind \& Braithwaite, 2002; Bolton et al., 2005).

${ }_{3}^{3}$ Players in public good games do not only punish free riders (Fehr \& Gächter, 2000), but also those who contributed too much (Herrmann, Thoni, \& Gachter, 2008). Austen-Smith and Fryer (2005) showed how pursuing behaviors associated with upward mobility can run the risk of alienating peers. Fear of appearing incentive motivated appears to be driving crowding out when monetary reward is given for prosocial behavior (Linardi and McConnell (2008), Ariely et al. (2009), Carpenter and Myers (2010), Lacetera and Macis (2010)). Recent evidence
} 
signaling a high level of altruism and hence will contribute more when observed, a wallflower will react to potential scrutiny by choosing an action closer to what she expects the "average person" to choose. This desire to avoid appearing significantly better or worse than others will induce a wallflower to increase her sensitivity to others' behavior when her actions will be revealed. In other words, she will increase her contribution when she expects others to give a lot and decrease it when others will give little. Thus, if wallflower preferences are prevalent, increased visibility will generate behavior that may appear as conditional cooperation and / or conformity. ${ }^{4}$

Some existing work is suggestive of wallflower preferences. For example, in a real effort volunteering experiment, Linardi and McConnell (2011) find that visibility increases the probability that participants quit volunteering when they observe others quitting. There are, however, a number of preferences that could lead to that result. In order to test for wallflower preferences, we need an environment with several characteristics. First, to identify the causal impact of visibility, information about what others do needs to be held constant while visibility is being manipulated. ${ }^{5}$ Second, to observe that individuals move towards what the average person does, it helps to observe their reaction to a distribution of giving, rather than a single moment of the distribution. Finally, an implication of wallflower preferences is that visibility will only positively impact giving when one expects others' giving to be high; thus, we would ideally observe reactions to visibility to a variety of social environments. Although many experiments, including Linardi and McConnell, incorporate some of these features, we are not aware of any that includes all three.

Our experimental design is as follows: participants are assigned to anonymous groups of three. In the first (unconditional) stage, participants decide how much to contribute to a charitable cause. Participants in the Baseline treatment are informed that their donations will be submitted in a sealed envelope at the end of the experiment. Participants in the Visibility treatment are told that their group will submit their donations in front of one another. In an unanticipated second stage, participants are given an opportunity to change their donation by conditioning their contribution on every possible combination of

from evolutionary biology suggests that moving towards the center of the group may be an instinctive way to protect oneself from unwanted attention (King et al., 2012).

${ }^{4}$ Conditional cooperation refers to giving a high amount in a public good game when others' contributions are high and giving a low amount otherwise (Fischbacher, Gachter, and Fehr, 2001). Conformity refers to the intrinsic desire to copy others' behavior, even when others are uninformed (Goeree and Yariv, 2007). Conformists are related, but not identical to wallflowers. For example, when everyone donates $\$ 4$, both types will give $\$ 4$. However, with two modes of giving at $\$ 0$ and $\$ 8$, a conformist will choose one of the modes while a wallflower will choose $\$ 4$.

${ }^{5}$ Croson, Handy, and Shang (2008) demonstrate that - even in the absence of visibility - a change in expectations about descriptive norms impacts giving. Visibility may simply impact participants' expectation about others' giving. Thus, it is important to hold information constant to truly understand whether participants are simply matching what they think is a new norm or whether reputation concerns are activated. 
the other two group members' donations. ${ }^{6}$ While the honor-seeking model predicts that Visibility will shift participants' contributions upwards, the wallflower model predicts that contributions will instead be drawn towards the middle of group members' donations.

We find evidence consistent with wallflower preferences. Average conditional contributions follow group members' hypothetical donations more closely in the Visibility treatment. As a result, visibility has a positive impact on contributions only in scenarios where group giving is high. A closer look at where contributions are placed reveals that participants are more likely to condition their donation to fall between their group members' contribution in the Visibility treatment. There is, however, no evidence that individuals respond to public recognition by conditioning their donations to fall above what others' might give. This, paired with an absence of a positive impact of visibility when others' giving is low, suggests a lack of honor-seeking behavior.

Following literatures suggesting that new donors (Shang and Croson, 2009) and women (Croson and Gneezy, 2009) may be more sensitive to their social environment, we also investigate if wallflower preferences are more prevalent amongst these groups. We find that women and individuals unfamiliar with the charitable cause are especially likely to choose contributions within the range of group members, suggesting heterogeneity in reputation concerns. Evidence of wallflower behavior is particularly striking for women: women in the Visibility treatment are almost twice as likely to condition their contributions to fall between their group members' contributions compared to women in the Control treatment. In addition, visibility appears to compress women's' unconditional contributions around their beliefs about average giving. ${ }^{7}$ A small-scale field experiment suggests that these gender differences generalize outside of the lab.

The first contribution of our paper is in providing a potential connection between the literature on prosocial reputation and the study of social influence. Field and laboratory experiments have shown that an individual increases her giving when provided with information that others have given a large amount and decreases it when given the opposite information (Frey \& Meier, 2004; Shang \& Croson 2008, 2009; Chen et al., 2008; Smith et al., 2012). A related literature on "conditional cooperation" documents a similar pattern in the context of laboratory public goods games (Fischbacher, Gachter, and Fehr, 2001; Bardsley and Sausgruber, 2005). However, because visibility is rarely manipulated in these experiments,

\footnotetext{
${ }^{6}$ We adapted the strategy method that Fischbacher, Gachter, and Fehr (2001) employed to show conditional cooperation in public good games to a charitable giving setup.

${ }^{7}$ Beliefs about the distribution of the first stage (unconditional) donations are collected at the end of the experiment through an incentivized elicitation procedure.
} 
this large body of literature has yet to be fully incorporated into the investigation of how public recognition affects prosocial behavior. Our findings suggest that increasing visibility amplifies the influence of information (or beliefs) about others' behavior on contributions because individuals are concerned about appearing neither too generous nor too stingy relative to others. This dependence on the prevailing (or perceived) level of contributions may help explain why visibility has not more consistently increase giving in the literature. ${ }^{8}$

The second contribution of our paper is in empirically identifying heterogeneity in reputation concerns. Women, in particular, appear to show the strongest propensity towards wallflower behavior by signaling that they are of "an average type" when observed. This result speaks not only to unresolved debates among fundraising practitioners about whether public recognition is an effective incentive for female donors (Taylor and Kaminski, 2004; Parsons, 2004; Hall, 2004; Kottasz, 2004), but also to a larger literature on gender differences in preferences. In a review of literature from psychology and economics, women's prosocial tendencies are found to be more sensitive to their social environment (Cox and Deck, 2006; Eckel and Grossman, 2008; Croson \& Gneezy, 2009). In addition, there is also a wealth of experimental evidence suggesting that women avoid competition (Niederle \& Vesterlund, 2007; Kanthak \& Woon, 2012). Wallflower preferences may be linked to this phenomenon. If "visibility" is perceived as introducing a competition for status, women may opt-out by choosing to signal that they are just "average".

The rest of the paper proceeds as follows. Section 2 presents a simple model of wallflower behavior. In Section 3, we discuss the design of our laboratory experiment. We present the result of our analysis in Section 4. Section 5 discusses the external validity of our laboratory findings and concludes.

\section{Model}

Our model builds on the honor/stigma version of Benabou \& Tirole's (2006) model of prosocial behavior (hereafter BT). Agents are (to varying degrees) intrinsically motivated to engage in prosocial behavior, but are also concerned about how their actions will be perceived by others. Unlike BT, whose model is driven by honor-seeking and stigma-avoidance, we assume that some agents - "wallflower" types - avoid both honor and stigma, and are therefore drawn to moderate their actions when observed.

\footnotetext{
${ }^{8}$ For example, if participants correctly anticipate the median giving in dictator game to be 50-50 under visibility, they will be less likely to give above and below 50-50 when identified, driving the behavior seen in Engel (2011) meta-study. Whether the move towards 50-50 increases donation depends on the distribution of participants' altruism.
} 
We first consider the case where agents make contribution decisions without information about others' behavior, then extend it to situations where this information is available.

An agent's intrinsic altruism is denoted by $v \sim u[0, A]$. Assume that agents choose between $N+1$ discrete contribution levels $a \in\{0,1,2, \ldots, N\}$ with cost function $C(a)$ where $C^{\prime}(a)>0$ and $C^{\prime \prime}(a)>0$. Following BT, let $v a$ represent the intrinsic benefit of prosocial behavior for an agent with altruism $v$ who contributed $a$. Let $x \in\{0,1\}$ denote whether contributions are linked to an agent's identity and publicized $(x=1)$ or not $(x=0)$. An agent's utility function is:

$$
u(a \mid x)=v a-C(a)+x R(a)
$$

where $R(a)$, the reputation benefit/cost associated with choosing $a$, is either experienced as "honor" or "stigma." When the altruism signaled by her action is higher than that of "the average person," the agent experiences honor; stigma is experienced when the opposite is true. The amount of honor or stigma experienced is measured by the distance from the average altruism type. Without information about who she will be compared to, an agent expects the average person to have an altruism of $\bar{v}=\mathrm{A} / 2$, the population average. Thus, honor is $R(a)=E[v \mid a]-\bar{v}$ while stigma is $R(a)=\bar{v}-E[v \mid a]$.

For honor-seeking agents, who correspond directly to BT's model, $R(a)$ is simply $E(v \mid a)-\bar{v}$ in both the honor and stigma domains. Note that $R(a)$ is increasing in contribution level $a$; also note that honor increases utility $(R(a)>0)$, while stigma decreases utility $(R(a)<0)$. Defining $r(a) \equiv R(a)-R(a-1)$ as the marginal reputational benefit of $a$, an honor-seeking agent who increases her giving to $a$ from $a-1$ experiences the following change in her reputation benefit:

$$
r(a)=(E[v \mid a]-\bar{v})-(E[v \mid a-1]-\bar{v})=E[v \mid a]-E[v \mid a-1]
$$

Individuals with wallflower preferences, however, are uncomfortable with any type of reputation; hence their utility decreases with both stigma and honor. For wallflower types, $R(a)=-|E[v \mid a]-\bar{v}|$, which is decreasing in the distance between the altruism of the average person and the altruism level signaled by $a .^{9}$ The marginal reputation benefit for a wallflower is:

$$
r(a)=|E[v \mid a-1]-\bar{v}|-|E[v \mid a]-\bar{v}|
$$

\footnotetext{
${ }^{9}$ This utility function is related to Bernheim's (1994) model of conformity. As in our model, Bernheim assumes individuals have an intrinsic desire to be viewed as a "moderate" type.
} 
To analyze the impact of increasing visibility, we focus on cutoff types, $\tilde{v}_{a}$ (the minimum altruism necessary for an individual to contribute $a) .{ }^{10}$ Letting $c(a) \equiv C(a)-C(a-1)$ denote the marginal cost of increasing $a$, the cutoff type for a contribution of $a$ is $\tilde{v}_{a}=c(a)-\operatorname{xr}(a)$. Note that any intervention that lowers $\tilde{v}_{a}$ for all contribution levels $a$ increases average contributions, while one that increases all $\tilde{v}_{a}$ decreases it.

When giving is anonymous $(x=0)$, there is no difference between wallflowers and honor-seeking types - cutoff types are solely defined by $c(a)$. When giving is publicly recognized, the two types behave differently due to their marginal reputation benefits $r(a)$. For honor-seeking types, honor is increasing in giving, so $r(a)$ (Eq. 2) is positive for all $a$. This implies that visibility will lower all cutoffs, thereby increasing contributions. On the other hand, a wallflower type's marginal reputation benefit is negative if a contribution of $a$ signals altruism that is further away from $\bar{v}$ than what is signaled by giving $a-1$ (Eq. 3). Importantly, this is true whether the agent is giving more or less than the average altruism type. As a result, visibility leads wallflower cutoff types to move away from $\bar{v}$. Denoting the contribution taken by a person of average altruism $\bar{v}$ as $a_{\bar{v}}$, wallflowers who had intended to give more (less) than $a_{\bar{v}}$ under anonymity will decrease (increase) their contributions when publicly recognized, resulting in more contributions clustered around $a_{\bar{v}}$.

Now suppose that before agent $i$ chooses a contribution $a_{i}$, she learns that agents $j$ and $k$ will contribute $a_{j}$ and $a_{k} \geq a_{j}$ respectively. How does this information mediate the impact of visibility on her giving? Festinger's (1954) Social Comparison Theory suggests that an individual's estimation of how well she is doing depends on to whom she is comparing herself. In this sense, agent $i$ 's reference point for the "average type" is no longer the population average $(\bar{v}=E(v))$ but instead is her group's average altruism: $\bar{v}_{j k}=\left(E\left[v \mid a_{j}\right]+E\left[v \mid a_{k}\right]\right) / 2$.

Replacing $\bar{v}$ with $\bar{v}_{\mathrm{jk}}$ in equations 2 and 3 illustrates how reputation concerns determine the degree to which social information influences an individual's public contribution. For honor-seeking types, $r(a)$ is always positive regardless of $\bar{v}_{j k}$ (Eq. 2). This implies that for any contribution pair $a_{j}$ and $a_{k}$, moving from an anonymous setting to one where donors are recognized will shift contribution upwards,

\footnotetext{
${ }^{10}$ In Appendix B we show the conditions under which $\mathrm{E}[\mathrm{v} \mid a]-\mathrm{E}[\mathrm{v} \mid a-1]>0$ in a model with three levels of giving. Cutoffs types can also be interpreted as the altruism of an individual who is indifferent between contributing $a$ or $a$ 1. Impact of an intervention on contributions can be described by its effect on cutoff types since average contribution is an increasing function of $\sum\left(\tilde{v}_{a+1}-\tilde{v}_{a}\right) a$.
} 
increasing the likelihood of observing $a_{i}$ above $a_{k}$. This is not true for wallflower types, since the sign of $r(a)$ (Eq. 3) depends on whether $E(v \mid a)$ is above or below $\bar{v}_{j k}$. Here, the effect of visibility will depend on social information: when $\bar{v}_{j k}$ is low, $r(a)$ will be negative for all but the lowest contribution levels, decreasing total giving. On the other hand when $\bar{v}_{j k}$ is high, $r(a)$ will be positive for all but the highest contribution levels, increasing total giving. In any case, increasing visibility will result in an increase in contributions between $a_{j}$ and $a_{k .}$.

\section{In summary, these preferences imply:}

- Given information $a_{j}$ and $a_{k} \geq a_{j}$ about $\mathrm{j}$ and k's contribution, wallflowers and honor-seeking types behave similarly in the absence of visibility.

- With visibility, honor-seeking types will increase their contributions. Visibility therefore increases the frequency of high contributions: $\operatorname{Pr}\left(a_{i}>a_{k}\right)$

- With visibility, wallflower types will adjust their contributions to signal that their altruism is average compared to $j$ and $k$. Visibility therefore increases the frequency of contributions between $a_{j}$ and $a_{k}: \operatorname{Pr}\left(a_{j}<a_{i}<a_{k}\right)$.

\section{Experimental Design}

We now turn to the design and results of our laboratory experiment. To test the implications of our model, it would be ideal to manipulate participants' beliefs about what others are giving and test whether the impact of visibility is increasingly positive (negative) depending on how high (low) others' giving may be. However, directly manipulating beliefs in the laboratory is not a straightforward task. We therefore assign participants to groups and use the strategy method to elicit their giving strategy conditional on the contributions of their group members who, in one of the treatments, will observe what they gave. ${ }^{11}$ By doing so, we are able to observe what a particular participant would choose to do under a variety of scenarios. In using the strategy method, we essentially test the impact of (hypothetical) social information at a within- rather than between-participant level.

\footnotetext{
${ }^{11}$ The conditional contribution elicitation is based on the design of Fischbacher et al. (2001), but with some important differences. Fischbacher et al. allow participants to condition on the mean of their group members' contributions whereas we allow participants to condition on every possible combination of group members' contributions.
} 
Participants were recruited through the Pittsburgh Experimental Economics Laboratory (PEEL) database. In each session, fifteen participants were seated at computer terminals upon arrival and randomly assigned to groups of three and identified only by anonymous participant IDs. We explained that the experiment would consist of a "giving task," during which they would have the opportunity to donate to a charitable cause, and a "guessing task," during which they would have the opportunity to earn "up to an additional $\$ 7 . "$

The software then played a slideshow describing the charitable cause: a water project in Tingo Pucara, Ecuador, organized by Engineers Without Borders (EWB) Pittsburgh, our partner nonprofit for the laboratory experiment. After the slide show, we endowed participants with 10 one-dollar bills in an envelope, from which they would make their contributions. Any money that participants did not donate was theirs to keep.

There are two treatments: Baseline and Visibility. The only difference between these two treatments is that Visibility treatment participants know that their identity will be revealed to their group members and the experimenter after all decisions have been made.

In the Baseline treatment, the instructions noted that:

"At the end of today's session, you will leave your donation in its original envelope on your desk. The software will inform you of your group's total donation to Tingo Pucara."

In the Visibility treatment, the instructions noted that:

"At the end of today's session, you and your group will sit down together around a table to submit your contributions. You will go to a different room with the experimenter who will then collect each group member's contributions, announce how much each person gave, and announce the total donation to Tingo Pucara. Your group members are the only participants who will observe how much you chose to give."

After these preliminaries were completed, the decision-making portion of the experiment consisted of three phases: (1) unconditional contributions, (2) conditional contributions, and (3) belief elicitation. These decision tasks are explained in detail below. Participants did not learn of the details of 
any of these phases until they occurred nor were participants aware that the "giving task" would ultimately consist of both an unconditional and conditional contribution task.

We conducted five sessions of each of the two treatments with 15 participants per session. There were (roughly) equal proportions of men and women in all ten sessions, with 75 men and 75 women participating overall. All sessions were conducted in the Pittsburgh Experimental Economics Laboratory (PEEL) using z-Tree software. Participants received a $\$ 5$ show-up fee in addition to any money kept or earned during the experiment. Sessions lasted less than one hour.

In the unconditional contribution task, participants were simply asked to indicate how much of their $\$ 10$ endowment they wanted to donate. We restricted contributions to multiples of $\$ 2$; that is, participants could choose to give $\$ 0, \$ 2, \$ 4, \$ 6, \$ 8$, or $\$ 10$. This restriction and the small group sizes were chosen to limit the number of choices that participants would face in the conditional contribution task.

In the conditional contribution task, participants were given the opportunity to change their contribution based on what the other two members of their group chose. Participants choose contributions conditional on every possible combination of their group members' contributions from the unconditional phase - a total of 21 decisions. ${ }^{12}$ For instance, in the first screen (Figure 1), a participant is asked to assume that one of their group members gave $\$ 0$ in the unconditional phase. A list of all possible unconditional contributions of the second member of their group ( $\$ 0, \$ 2, \$ 4, \$ 6, \$ 8$ and $\$ 10)$ is displayed, and the participant is asked to indicate her donation for each combination of hypothetical contributions. A similar series of screens then follows. In the second screen, participants are asked to assume one group member gave $\$ 2$ and to then indicate how she would contribute if the second group member gave $\$ 2, \$ 4$, $\$ 6, \$ 8$, or $\$ 10$. The following screens present the rest of the scenarios, fixing one group member's contribution at $\$ 4, \$ 6, \$ 8$ and $\$ 10$.

\footnotetext{
${ }^{12}$ This is the same number of decisions that participants make in Fischbacher et al.'s (2001) experimental design. Fischbacher et al. (2012) document the behavioral validity of this method: individuals who conditionally cooperate under the original strategy method design also do so under the direct response method.
} 


\section{Figure 1: Conditional contribution entry}

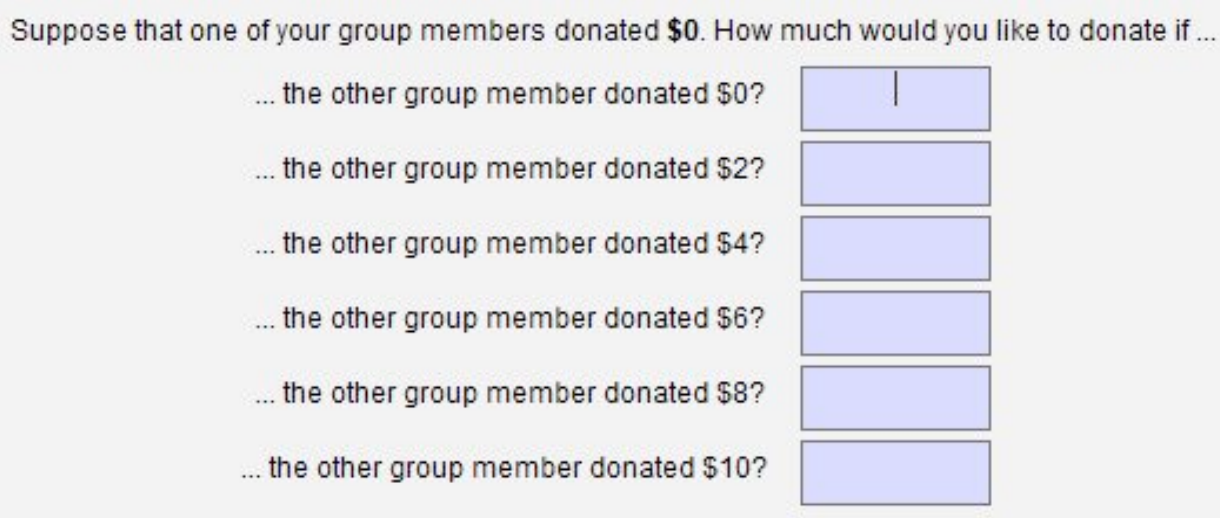

As in the conditional contribution design of Fischbacher et al. (2001), one member of each group was randomly selected at the end of the session to have her conditional contribution implemented. Thus, when participants submitted their contributions at the end of the experiment, two members of each group submitted the contribution they chose in the unconditional phase and the remaining member submitted the relevant conditional contribution. Even in the Visibility treatment, participants never learned which member of their group was randomly selected to have his or her conditional contribution implemented.

In the belief elicitation task, participants were asked to guess the number of people who chose each of the possible unconditional contributions. Participants were informed that they had 14 tokens (one for each of the other participants in the room) to allocate across the possible unconditional contributions $(\$ 0, \$ 2, \$ 4, \$ 6, \$ 8$, and $\$ 10)$. Each token that was placed correctly earned the participant $\$ 0.50-$ participants can earn up to $\$ 7$ in this task. ${ }^{13}$ Denoting a participant's reported guess of the number of participants who chose unconditional contribution $k$ as $g_{k}$ and the actual number of participants as $n_{k}$, then the belief elicitation payoff can be expressed as:

$$
\sum_{k} 0.5 * \min \left\{g_{k}, n_{k}\right\} \text { for } k \in\{0,2,4,6,8,10\}
$$

After completing the belief elicitation task, participants completed a brief survey where they indicated their gender and familiarity with the charitable cause. ${ }^{14}$ They were next informed of (1) their earnings from the belief elicitation task, (2) the actual contribution they would provide based on whether

\footnotetext{
${ }^{13}$ See Appendix $\mathrm{C}$ for a proof of the incentive compatibility of this belief elicitation procedure.

${ }^{14}$ There is no evidence of a gender difference in familiarity to the organization (EWB). Nationally, $45 \%$ of EWB members are women.
} 
or not they were the randomly selected member of their group and, if so, the unconditional contributions of their group members, and (3) their group's total contribution to the cause. Donations were then collected according to the procedures described above.

\section{Results}

In this section we will describe simple summary statistics and determinants of giving (4.1), before turning towards our main hypothesis that participants position their contribution to signal that they are "average" relative to their social group (4.2). We will then examine potential sources of heterogeneity in reputation concerns, namely participants' familiarity with the social cause and gender (4.3).

\subsection{Summary statistics and determinants of conditional contributions}

Table 1 reports summary statistics from all phases of the experiment: unconditional contributions, conditional contributions, and elicited beliefs. Giving is low: modal giving is $\$ 0$ in the baseline condition and $\$ 2$ in the visibility condition. In both the unconditional and conditional phases of the experiment, the raw means of contributions are slightly higher under visibility but not significantly so. Using elicited beliefs to calculate participants' expected value of other's unconditional contribution, we see that participants' beliefs about mean unconditional contribution (Row 3 of Table 1) are also not significantly higher. ${ }^{15}$ However, on average, participants' beliefs do correctly anticipate that modal giving will shift from $\$ 0$ to $\$ 2$ with visibility. ${ }^{16}$

Figure 2 plots the relationship between participants' conditional contributions and the mean of their group members' hypothetical contributions. The light gray line shows that relative to the Baseline treatment, Visibility does not uniformly increase contributions. Instead, the impact of visibility depends on what others may be giving. In this environment where the majority of contributions are $\$ 0$ and $\$ 2$, visibility has a small, insignificantly negative effect on giving when group members may be giving the minimum $(\$ 0)$. Visibility starts to have significant positive effect on contributions as group mean rises,

\footnotetext{
${ }^{15}$ We generate participants' probability distribution over other participants' contribution by dividing participants' reports by the number of other participants (14). For example, if a participant believes that 7 participants have given $\$ 0$, we take this participant to believe that the probability of a $\$ 0$ contribution is $7 / 14=0.5$. E [unconditional contribution] is calculated using this probability distribution.

${ }^{16}$ Participants anticipated $29 \%$ of participants in Baseline to give $\$ 0$ and $24 \%$ to give $\$ 2$. These proportions changed to $20 \%$ and $30 \%$ in Visibility.
} 
increasing contributions by $33 \%$ (difference of $\$ 1.34$, p-value $=0.017$ ) when the mean of group members' contributions is $\$ 10$.

Table 1: Summary statistics -- Means of outcome variables

\begin{tabular}{lccc}
\hline & Control & Visibility & $\begin{array}{c}\text { p-value (two- } \\
\text { tailed t-test) }\end{array}$ \\
\hline Unconditional contribution & 3.333 & 4.133 & 0.16 \\
& $(0.408)$ & $(0.395)$ & 0.22 \\
Conditional contribution ${ }^{1}$ & 3.010 & 3.641 & 0.79 \\
& $(0.381)$ & $(0.348)$ & \\
Belief: E[uncond. cont.] & 3.396 & 3.484 & \\
& $(0.242)$ & $(0.219)$ & \\
& & & \\
Observations & 75 & 75 \\
\hline Standard errors from mean of within-participant averages in parentheses.
\end{tabular}

Figure 2: Average conditional contributions as a function of average hypothetical group contribution

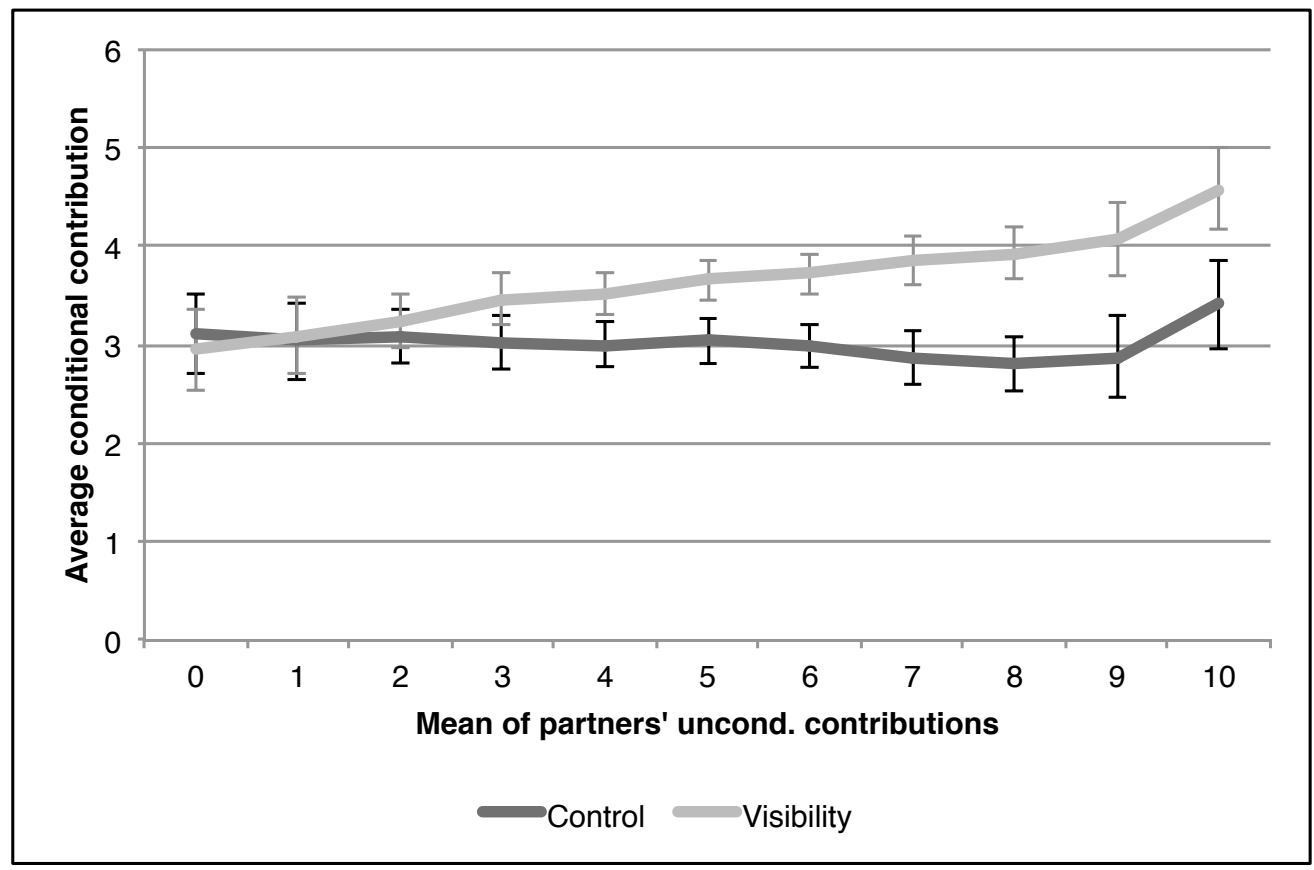

Standard error bars displayed

We confirm our findings with linear regressions in Appendix Table A1 where we regress conditional contributions against group mean, the Visibility treatment dummy, and the interaction of 
visibility and group mean. Models 1-3 include all observations. We find that hypothetical group mean has no impact on conditional contribution in the Baseline treatment, but has a significant positive impact on contributions in the Visibility treatment $(\mathrm{p}<0.01$, Column 2 and 3$)$. One concern with the strategy method is that some scenarios may be viewed as unlikely by participants, which may result in less meaningful responses. Models 4-6 include only 56\% of the total observations after excluding scenarios that participants think are unlikely to occur. These are observations for which a participant thinks the scenario in question will not occur because she has assigned a probability of zero to one or both of the hypothetical contributions of group members. When we drop unlikely scenarios, we find that hypothetical group mean does have a positive impact in both treatments but is further amplified by the Visibility treatment $(\mathrm{p}<0.10$, Column 5 and 6).

Lab Experiment Finding 1: Visibility does not uniformly increase contributions. Conditional contributions follow group members' hypothetical donations more closely in the Visibility treatment. As a result, visibility only has a positive impact in scenarios where group giving is above the modal contribution.

This finding provides some evidence for wallflower preferences and against honor-seeking preferences. However, this pattern of behavior is also consistent with other reputation concerns such as the desire to match group members' contributions (conformity) or a desire to seek honor at the lowest cost (by conditioning contributions to fall just above the maximum of group members' contributions). In the next subsection, we attempt to isolate wallflower preferences by examining where participants position their contributions.

\subsection{Positioning of contributions}

Our model suggests that while honor-seekers are drawn towards actions that signal high types, wallflowers gravitate towards actions that signal that they are average relative to their group members. In this section we test our main hypothesis: given information $\left(a_{j}, a_{k} \geq a_{j}\right)$ about participant $j$ and $k$ 's potential contributions, visibility increases the probability that participant $i$ chooses "middle" actions $\left(a_{j}<\right.$ $\left.a_{i}<a_{k}\right)$ and decreases the probability of extreme actions $\left(a_{i}<a_{j}\right.$ and $\left.a_{i}>a_{k}\right)$.

We estimate a series of linear probability models assessing the likelihood that a conditional contribution falls within a particular position relative to her group members' (hypothetical) contributions. The range of contributions that we are interested in are: (1) less than the minimum $\left(a_{i}<a_{j}\right)$, (2) equal to 
the minimum $\left(a_{i}=a_{j}\right)$, (3) within range $\left(a_{j}<a_{i}<a_{k}\right)$, (4) equal to the maximum $\left(a_{i}=a_{j}\right)$, or (5) greater than the maximum $\left(a_{i}>a_{k}\right)$. Thus, we estimate a set of regressions of the form:

$$
y_{i s}^{r}=\alpha+\beta_{v} V i s_{i}+\delta_{s}
$$

where $y_{i s}^{r}=1$ if participant $i$ chooses a contribution within the associated range $r$ in her scenario $s \in\{1, \ldots, 21\}$. Note that it is not always possible to choose a contribution within a particular range. For instance, when the minimum of partners' contributions is 0 , it is impossible to choose a contribution "less than the minimum." These instances are excluded from the analysis. ${ }^{17}$ To allow the most flexibility in accounting for the 21 different scenarios where participants make decisions, we include $\delta_{s}$ (scenario fixed effects), which are simply dummy variables for each of these scenarios. ${ }^{18} \mathrm{Vis} s_{i}=1$ if participant $i$ is in the Visibility treatment and 0 otherwise.

Panel A of Table 2 reports our main results. Contrary to honor-seeking preferences, there is no evidence that visibility increases contributions that are above group members' contributions (Column 5). Instead, there is an increase in the number of contributions that fall within the range of group members' contributions (Column 3). We also see evidence of a decrease in contributions that are extremely low ( $<$ Min.) (Column 1). There is little evidence of a decrease in contributions that are extremely high relative to group members (Column 5), but this may be in part because high contributions are generally rare. This motivates a more targeted test of wallflower preferences in Panel B.

Recall that in our model, visibility impacts "cutoff types" by increasing or decreasing the level of altruism necessary to choose a particular action. If wallflower preferences are prevalent, visibility pulls participants' contributions marginally closer to the contribution of the "average altruism type" than they otherwise would have been. With this in mind, in Panel B we focus on "marginal types": participants whose unconditional contributions were just above ( $\$ 2$ higher than) the maximum of group member contributions $\left(a_{k}\right)$ and individuals whose unconditional contributions were just below ( $\$ 2$ below) the minimum $\left(a_{j}\right)$. We modify the main specification (from Panel A) to allow for an interaction between

\footnotetext{
${ }^{17}$ Other exclusions: It is impossible to be "greater than maximum" when the maximum contribution is 10 , so all such cases are excluded from "greater than max." regression. It is impossible to be strictly "within range" when the distance between partners' contributions is 0 or 2 , so these cases are excluded from "within range" regression. Finally, there is no unique maximum or minimum when partners' contributions are identical, so these cases are excluded from the "equal to min." and "equal to max." regressions.

${ }^{18}$ This is more flexible than using a summary statistic of others' contributions as a control variable (e.g group mean in Appendix Table 1), since it accounts for different responses to scenarios with the same summary statistic (e.g., $\$ 0$ and $\$ 10$ may be viewed differently by participants than $\$ 4$ and $\$ 6$ ).
} 
visibility and dummy variables indicating that an individual's unconditional contribution is just below the minimum ("Just below") or just above the maximum ("Just above").

Table 2: Likelihood that a contribution falls within a particular range (OLS)

\begin{tabular}{|c|c|c|c|c|c|}
\hline \multirow[b]{2}{*}{ VARIABLES } & (1) & $(2)$ & (3) & $(4)$ & (5) \\
\hline & $<$ Min & $=$ Min & Within range & = Max. & > Max. \\
\hline \multicolumn{6}{|c|}{ PANEL A: Impact of visibility } \\
\hline \multirow[t]{2}{*}{ Vis. } & $-0.112 *$ & 0.0222 & $0.0720 *$ & 0.0258 & -0.0089 \\
\hline & $(0.0577)$ & $(0.0233)$ & $(0.0419)$ & $(0.0248)$ & $(0.0510)$ \\
\hline \multirow[t]{2}{*}{ Constant } & $0.611 * * *$ & $0.228 * * *$ & $0.244 * * *$ & $0.108^{* * *}$ & $0.212 * * *$ \\
\hline & $(0.0420)$ & $(0.0145)$ & $(0.0289)$ & $(0.0173)$ & $(0.0368)$ \\
\hline Observations & 2,250 & 2,250 & 1,500 & 2,250 & 2,250 \\
\hline R-squared & 0.178 & 0.050 & 0.141 & 0.036 & 0.107 \\
\hline
\end{tabular}

PANEL B: Impact of visibility on marginal types

\begin{tabular}{|c|c|c|c|c|c|}
\hline Vis. (Just Above) & $\begin{array}{c}0.0194 \\
(0.0666)\end{array}$ & $\begin{array}{c}0.0355 \\
(0.0452)\end{array}$ & $\begin{array}{c}0.0460 \\
(0.0659)\end{array}$ & $\begin{array}{l}0.200 * * \\
(0.0850)\end{array}$ & $\begin{array}{c}-0.272 * * \\
(0.106)\end{array}$ \\
\hline Vis. (Just Below) & $\begin{array}{l}-0.136 * * \\
(0.0570)\end{array}$ & $\begin{array}{l}0.126 * * \\
(0.0526)\end{array}$ & $\begin{array}{c}0.000354 \\
(0.0221)\end{array}$ & $\begin{array}{c}0.00853 \\
(0.00671)\end{array}$ & $\begin{array}{r}-0.00124 \\
(0.0131)\end{array}$ \\
\hline Constant & $\begin{array}{c}0.529 * * * \\
(0.0372)\end{array}$ & $\begin{array}{c}0.285 * * * \\
(0.0199)\end{array}$ & $\begin{array}{c}0.295 * * * \\
(0.0321)\end{array}$ & $\begin{array}{c}0.125^{* * *} \\
(0.0187)\end{array}$ & $\begin{array}{c}0.180 * * * \\
(0.0337)\end{array}$ \\
\hline Observations & 2,250 & 2,250 & 1,500 & 2,250 & 2,250 \\
\hline R-squared & 0.394 & 0.091 & 0.192 & 0.076 & 0.240 \\
\hline
\end{tabular}

Additional evidence of wallflower preferences emerges after identifying these marginal types (Table 2, Panel B). Participants who initially chose a contribution just above $a_{k}$ are significantly more likely to decrease their contribution to $a_{k}$ (Column 5 and 6), therefore moving towards the center. Similarly, those who initially chose a contribution just below $a_{j}$ also move towards the center by increasing their contributions to $a_{j}$ (Column 1 and 2). Results are qualitatively similar, though sometimes less precisely estimated, when scenarios that participants perceive as unlikely are excluded (Appendix Table A2). 
Figure 3: Individual-level frequency of "within range" contributions

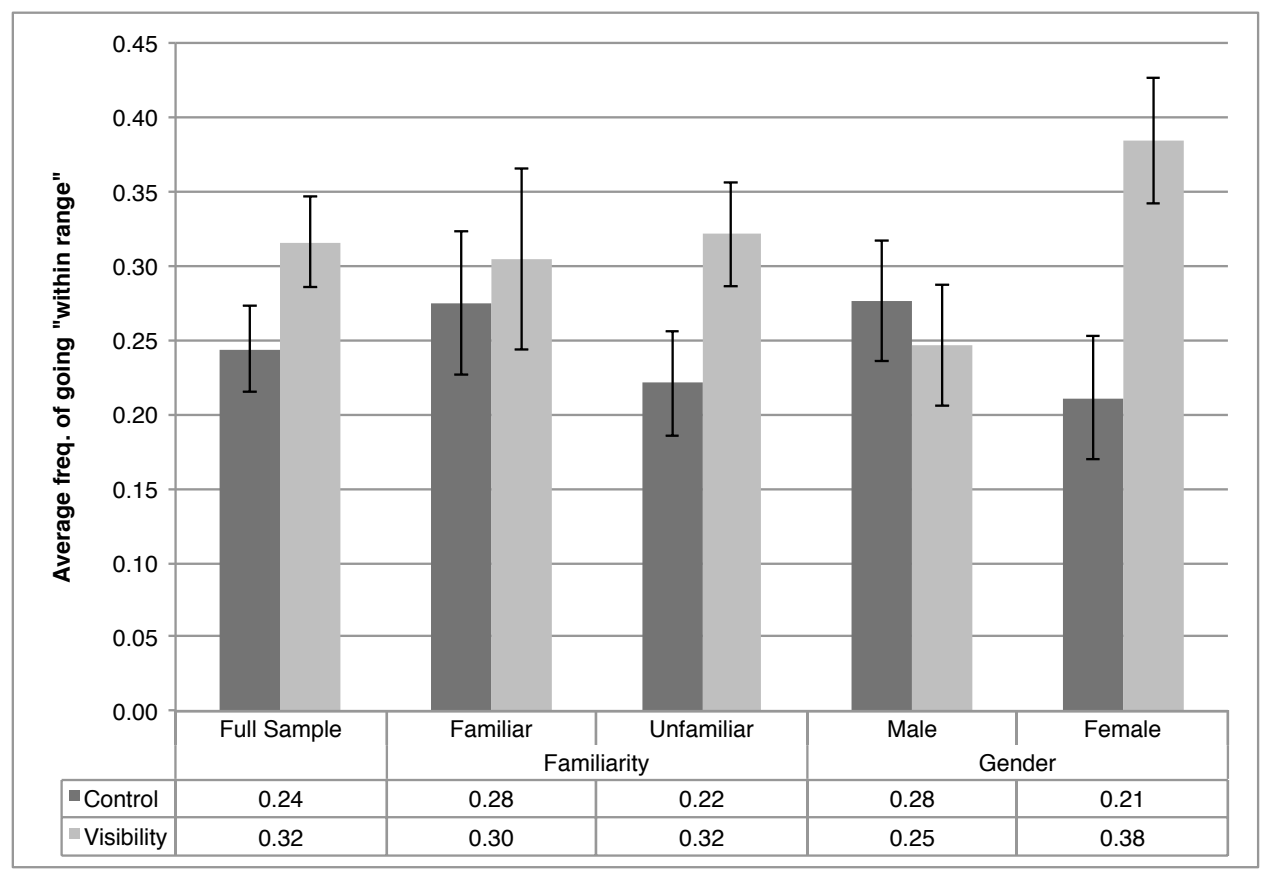

Standard error bars are displayed

Alternatively, we can take an individual as the unit of observation and assess the frequency with which she conditions her contributions to fall within the range of her partners' contributions. On average, participants in the Baseline treatment choose "within range" contributions $24 \%$ of the time. This proportion increases to $32 \%$ for participants in the Visibility treatment (Figure 3 Full Sample). The difference is significant at the $10 \%$ level.

Lab Experiment Finding 2: Consistent with wallflower preferences, visibility increases the proportion of contributions that fall within the range of group members' contribution; contributions that were just above or just below group members' contributions are especially likely to be revised towards the center. There is no evidence that visibility encourages contributions that are above other group members' contributions.

\subsection{Heterogeneity in reputation concerns}

The previous section provides evidence of wallflower preferences. In this subsection we ask if these preferences are more common among certain participants than others. Previous literature suggests two possible dimensions where heterogeneity in reputation concerns may be observed: familiarity with the charitable cause and gender. Experiments with public radio listeners have shown that individuals who 
have less experience with a charitable cause are more likely to be influenced by social information (e.g., Shang \& Croson, 2009). For those who are not very knowledgeable about a social cause, extrinsic motivation, including reputation concerns, may play a larger role in contribution decisions relative to intrinsic altruism. On gender, research in psychology has found women to more readily conform when observed by a group than men (Eagly, 1978; Eagly \& Carli, 1981; Bond \& Smith, 1996). In addition, a large literature in economics suggests that there are gender differences in prosocial behavior, especially in environments where one may be judged by others (Croson and Gneezy, 2009; Eckel and Grossman, 2008; DellaVigna et al., 2013). ${ }^{19}$ It is therefore possible that the fear of unwanted attention -- being judged or alienated for being either too bad or too good -- is more relevant for women, which may then imply that wallflower preferences will more prevalent among women.

We test for heterogeneity in reputation concerns by modifying the main empirical specification (Eq. 5) to allow for interactions between visibility and familiarity (Table 3, Panel A), and visibility and gender (Table 3, Panel B). Both the familiarity measures and gender were collected in the short survey conducted just after the session. In Panel A of Table 3, we find that there is no significant effect of visibility on those who are familiar with the cause. On the other hand, individuals who are unfamiliar with the cause are less likely to give a low amount (Column 1) and more likely to choose a contribution within $a_{j}$ and $a_{k}$ (Column 3$)$ when their contributions are revealed.

In Panel B, we find that women are significantly more likely to choose a contribution within range when visible Column (3) and (insignificantly) less likely to choose a contribution below the minimum or above the maximum of group members' contributions. Men do not respond to visibility in a statistically significant manner. When observations from scenarios that participants find unlikely are excluded (Appendix Table 3), we find stronger evidence of men and women moving inwards in response to visibility. While men appear to be matching the max, there is even stronger evidence of women's increased propensity to move "within range.",21

Figure 3 from the previous section provides a concise summary of our findings. While the propensity to choose within-range contributions increases from $28 \%$ to $30 \%$ (p-val $>0.10$ ) for participants who are familiar with the charitable cause, those who are unfamiliar with the cause increase from $22 \%$ to $32 \%$ (p-val $<0.05$ ). The differential response to visibility across gender is even more

\footnotetext{
${ }^{19}$ Zetland and Della Giusta (2011) show that only women change their public good game contribution in response to the salience of information.

${ }^{21}$ If "conformity" is defined as matching what another participant has chosen, this provides some evidence that men can be seen as "conformists" while women are wallflowers.
} 
pronounced. While men choose within-range contributions $28 \%$ of the time in Baseline and $25 \%$ of the time in Visibility ( $\mathrm{p}$-val $>0.10$ ), women choose within-range contributions $21 \%$ of the time in Baseline and $38 \%$ of the time in Visibility. This difference is significant at the $1 \%$ level.

Table 3: Likelihood of choosing a contribution within a particular range - Heterogeneous responses (OLS)

\begin{tabular}{lccccc}
\hline & $(1)$ & $(4)$ & $(5)$ & $(6)$ & $(3)$ \\
VARIABLES & $<$ Min. & $=$ Min. & Within range & $=$ Max. & $>$ Max. \\
\hline
\end{tabular}

PANEL A: Differential response to visibility by Familiarity with Cause

\begin{tabular}{lccccc} 
Vis. (Familiar) & -0.134 & 0.0240 & 0.0293 & 0.0572 & 0.0082 \\
& $(0.0956)$ & $(0.0430)$ & $(0.0767)$ & $(0.0433)$ & $(0.0974)$ \\
Vis. (Unfamiliar) & $-0.131^{*}$ & 0.0137 & $0.100^{* *}$ & 0.0191 & 0.0062 \\
& $(0.0688)$ & $(0.0278)$ & $(0.0496)$ & $(0.0313)$ & $(0.0563)$ \\
Constant & $0.517^{* * *}$ & $0.202^{* * *}$ & $0.275^{* * *}$ & $0.131^{* * *}$ & $0.287^{* * *}$ \\
& $(0.0681)$ & $(0.0221)$ & $(0.0480)$ & $(0.0219)$ & $(0.0630)$ \\
& & & & & \\
Observations & 2,250 & 2,250 & 1,500 & 2,250 & 2,250 \\
R-squared & 0.203 & 0.052 & 0.143 & 0.044 & 0.131 \\
\hline
\end{tabular}

PANEL B: Differential response to visibility by Gender

\begin{tabular}{lccccc} 
Vis. (Male) & -0.0853 & 0.0371 & -0.0304 & 0.0364 & -0.0057 \\
Vis. (Female) & $(0.0778)$ & $(0.0326)$ & $(0.0571)$ & $(0.0278)$ & $(0.0700)$ \\
& -0.136 & 0.0084 & $0.173^{* * *}$ & 0.0139 & -0.0133 \\
Constant & $(0.0839)$ & $(0.0330)$ & $(0.0589)$ & $(0.0406)$ & $(0.0742)$ \\
& $0.646^{* * *}$ & $0.239^{* * *}$ & $0.276^{* * *}$ & $0.0789^{* * *}$ & $0.188^{* * *}$ \\
& $(0.0532)$ & $(0.0165)$ & $(0.0403)$ & $(0.0152)$ & $(0.0458)$ \\
Observations & & & & & \\
R-squared & 2,250 & 2,250 & 1,500 & 2,250 & 2,250 \\
\hline
\end{tabular}

Standard errors in parentheses, clustered at individual-level. Scenario fixed effects are included. $* * * \mathrm{p}<0.01, * * \mathrm{p}<0.05, * \mathrm{p}<0.1$

Finally, we check whether wallflower behavior is an artifact of the strategy method used in the conditional contribution stage by analyzing the distance between participants' unconditional contributions and their reported expectation of others' contributions. ${ }^{22}$ Specifically, we construct "belief-normalized contributions" as the uncond $_{i}-E_{i}$ [uncond $\left._{-i}\right]$, where uncond $_{i}$ is participant $i$ 's unconditional contribution and $E_{i}$ [uncond $\left.{ }_{-i}\right]$ is participant $i$ 's belief about the average contribution of others. Note that

\footnotetext{
${ }^{22}$ This quantity was calculated from elicited beliefs in the same way for Table 1 Row 3. See Section 4.1 for details.
} 
a belief-normalized contribution of zero indicates that a participant chooses a contribution that matches her expectation of others.

While we do not find significant evidence of differences in reputation concerns across levels of familiarity (Appendix Figure A1), there are gender differences. Figure 4 plots distributions of beliefnormalized contributions by treatment and gender. While visibility compresses women's contributions around their expectation of others' behavior; this phenomenon is not true of men. Indeed, variance-ratio tests reveal that the variance of women's (but not men's) belief-normalized contributions decreases with visibility (one-tailed t-test $\mathrm{p}$-val=0.061), while the mean of men's (but not women's) belief-normalized contributions increases (one-tailed t-test $\mathrm{p}$-val $=0.071){ }^{23}$

Figure 4: Distributions of belief-normalized contributions

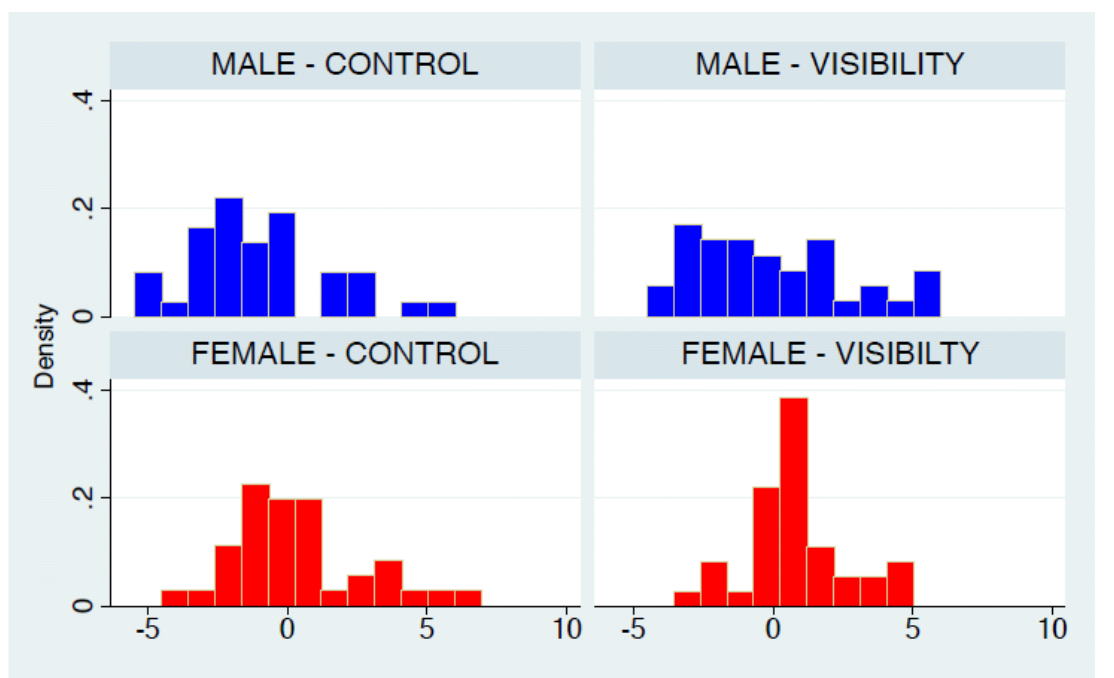

Lab Experiment Finding 3: We find heterogeneity in reputation concerns. Wallflower behavior is particularly prevalent amongst women and individuals unfamiliar with the cause. Both groups are significantly more likely to choose contributions within the range of group members' contributions when visible. The evidence is stronger for women and is also observed outside of the strategy method.

\section{Conclusion}

\footnotetext{
${ }^{23}$ A Kolmogorov-Smirnov test rejects the hypothesis that women's "belief-normalized contributions" across control and visibility treatments are drawn from the same distribution (p-val.=0.065). This null hypothesis cannot be rejected for men $(p-v a l .=0.475)$. We conducted similar tests for participants familiar and unfamiliar with the cause, but find no important differences. Visibility increases the mean of "belief-normalized" giving for both familiar and unfamiliar participants, but does not differentially impact the variance of giving across groups.
} 
In this paper, we revisit the question of how visibility impacts prosocial behavior. We theoretically propose a novel response to visibility: "wallflower" behavior, or an aversion to standing out in either a positive or negative way. These preferences imply that individuals will respond to visibility by avoiding actions that are either very low or very high relative to others, thereby driving individuals' choices towards what they think is the mean of the distribution of actions.

We provide evidence of such behavior in a laboratory experiment. Participants are able to choose a donation to a charitable cause conditional on every possible combination of the donations of their two group members, who - in the Visibility treatment - will observe how much they donated. Consistent with the theoretical predictions, we find that visibility significantly increases the likelihood that a participant chooses within-range contributions - contributions that fall between his/her group members' contributions. We also observe heterogeneity in reputation concerns. Compared to those who were familiar with the charitable cause, individuals who were unfamiliar with the cause were more likely to respond to observation by choosing within-range contributions. The strongest evidence of wallflower preferences, however, appears to come from women. Female participants in the Visibility are not only twice as likely to choose within-range contributions relative to female participants in Baseline, but also choose unconditional contribution that are closer to their beliefs about the average participant's contribution.

A small-scale fundraising experiment we conducted at a campus fair suggests that females' wallflower tendency is also present outside of our lab setting. ${ }^{24}$ We set up a word search game booth using five computers that are separated by partitions. In the game a $15 \times 15$ grid of jumbled letters hides 12 words. For every word found, 15 cents are donated to a water project in Ecuador. Fair attendees who stop by the booth can play the game for as long as they wish. When one grid is completed, another appears. Clicking on a quit button terminates the game and directs participants to a short demographic survey. Participants are randomly assigned to one of two treatments: Scores or Names. ${ }^{25}$ In the Scores treatment, the dollar amount raised by previous players is displayed before the game starts. ${ }^{26}$ In the Names treatment, participants are first asked to enter their name; they are then shown the dollar amount

\footnotetext{
${ }^{24}$ We partnered with Engineers for a Sustainable World (ESW) to hold the fundraising at the California Institute of Technology Club Fair. This annual fair is attended by more than 1000 people from the community. Partitions are set up such that only one person can be at each computer.

${ }^{25}$ A Baseline treatment was also conducted, but is not discussed here. In the Baseline treatment participants simply played the word search game without receiving any information about the donations of previous participants and without being asked to enter their name. In total we had 104 participants, 71 in Scores and Names. 20 participants without starting the survey and hence their gender information is not available.

${ }^{26}$ The listing for both Scores and Names includes only the last 10 people on that computer.
} 
and names of previous players. They are aware that future participants will observe their name and donation.

On average, participants spend 5.5 minutes working and contribute $\$ 2.25$, which corresponds to finding 15 words. A modal contribution emerges: roughly half of all participants stop after completing the first grid, finding exactly 12 words and contributing \$1.80. Men's donations went from $\$ 2.79$ in Scores $(\mathrm{N}=17)$ to $\$ 2.94$ in Names $(\mathrm{N}=10)$. However, women's donations decreased from $\$ 3.15$ in Scores $(\mathrm{N}=12)$ to $\$ 2.08$ in Names $(\mathrm{N}=12)$. Figure 6 shows that the drop in giving is not due to a simple downward shift: when names are displayed, women in the Names treatment are more likely to choose the modal contribution of $\$ 1.80$ ( $\mathrm{p}$-val $=0.136$ ). More generally, visibility significantly decreases the distance between a woman's donation and $\$ 1.80\left(\mathrm{p}\right.$-val=0.087). Neither pattern is observed among males. ${ }^{27}$

Figure 6: Freq. of donations below, equal to, and above $\$ 1.80$ by treatment and gender

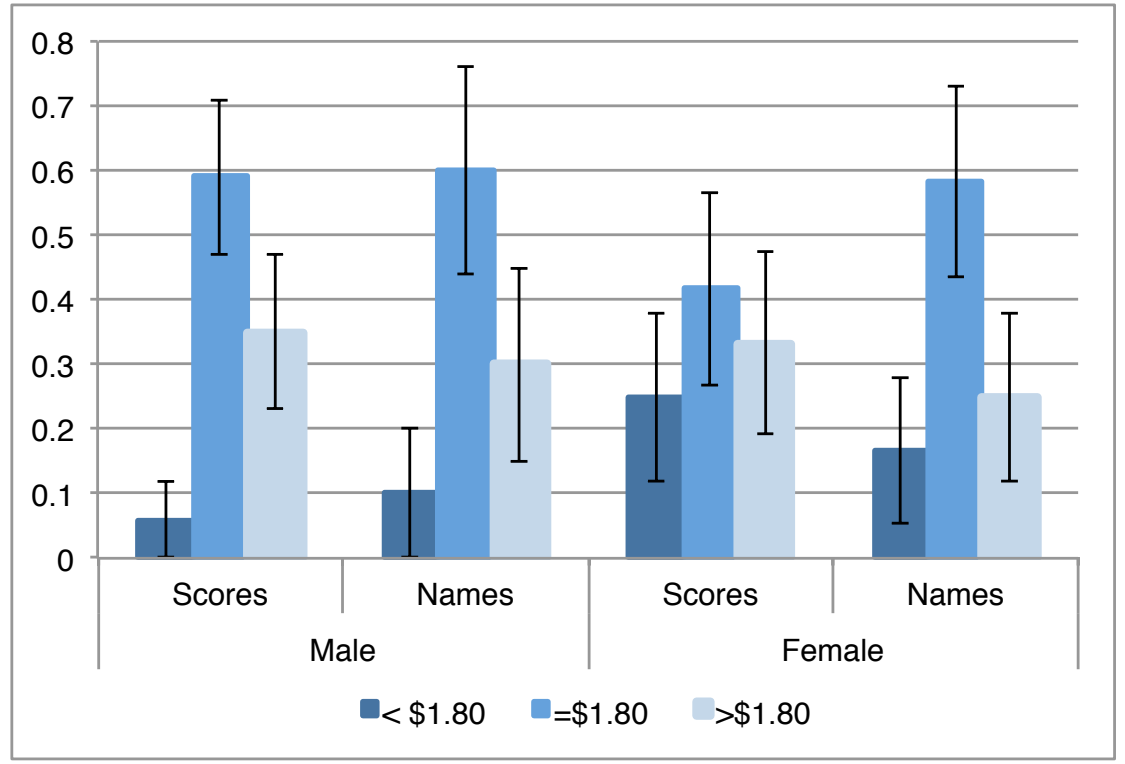

Thus, in both the lab and in our small-scale field experiment, we find that women are especially likely to choose what the average person would do when their prosocial behavior is publicized. This may suggest that women are more concerned than men about standing out or being judged as image motivated. This fear may relate to women's reluctance to engage in competition (Niederle and Vesterlund, 2007; Pan and Houser, 2012; Kanthak and Woon, 2012). Hence, women behave as wallflowers (choosing middle

\footnotetext{
${ }^{27}$ See Appendix Table A4. Column 1 is a linear probability model on the impact of "Names" on the likelihood of choosing $\$ 1.80$. Column 2 is an OLS on the distance between donation and $\$ 1.80$.
} 
actions) in order to opt-out of the status competition that may be introduced when actions are publicly recognized.

How do our findings relate to the literature investigating the relationship between visibility and prosociality? While most of the existing experimental work tests the hypothesis that visibility increases giving, our findings suggest that this relationship may be more complex. Specifically, it appears that individual characteristics and beliefs about what others are giving mediate the effect of visibility on an individual's contribution. Because past experiments have rarely collected beliefs about what others are doing and individual characteristics, we can only speculate on how our findings on reputation avoidance explain the occasional divergent results in the literature. In dictator games, wallflowers should respond to visibility by moving away from contributions higher or lower than an equal division if they correctly anticipate that others will choose an equal division when observed; there is evidence that they do so (Engel, 2011). ${ }^{28}$ Similarly, in a public goods game we might expect conditional cooperation among wallflowers to increase with visibility. ${ }^{29}$ While we find that women are especially likely to display wallflower preferences, individual characteristics that determine heterogeneity in reputation concerns are likely to be richer than gender. ${ }^{30}$ Linking behavior to social information, beliefs, and individual characteristics (and the interaction thereof) may play an important role in future efforts to understand the role of public recognition in increasing prosocial behavior.

Finally, our findings suggest that care must be taken in manipulating the degree of visibility of prosocial behavior. There is some debate in the nonprofit and fundraising literature about whether public recognition is a worthwhile fundraising tool for women. (Taylor \& Kaminski, 2004; Hall, 2004; Parsons, 2004; Kottasz, 2004). Our results suggest that the answer to this question highly depends on context.

\footnotetext{
${ }^{28}$ The mode in dictator games to shift from 0 to .5 if dictators are identified (Engel, 2011). Participants may anticipate this change in giving since the $50-50$ split is generally identified as the "most appropriate" action in a dictator game (Krupka and Weber, 2012). We reanalyzed some existing experimental data on dictator giving to see whether there is evidence that women are more likely than men to give half of their endowment under visibility. Splitting Andreoni and Bernheim (2009) by gender, we find that while $41 \%$ (53\%) of women give 50-50 when there is a $25 \%(75 \%)$ chance that they will be identified, only $20 \%(35 \%)$ of men do so. This difference is smaller $(65 \%$ women, $60 \%$ men) when dictators will certainly be identified. Dufwenberg and Muren's (2008) visibility condition is an exception to Engel's observation: the mode was 50-50 without visibility and shifted to 0 with visibility. Even so, while the proportion of men who give 50-50 decreases from $40 \%$ to $26 \%$ with visibility, the proportion of female who give $50-50$ decreased less, only going from $40 \%$ to $35 \%$.

${ }^{29}$ In a reanalysis of data from Fehr and Gachter (1999), we find that women are conditionally cooperative in the visibility treatment but not in the baseline treatment. This is similar to what is observed by Meier (2005).

${ }^{30}$ For example, Serra and Salmon (2013) show that propensity to follow rules differ by culture (country of origin). Our finding on familiarity suggests that reputation concerns also depend on donors' degree of comfort with the organization.
} 
When the average person gives a small amount and there is a large proportion of wallflowers (i.e. women), visibility may not be the best environment to encourage prosocial behavior. 


\section{References}

Alpizar, F., Carlsson, F., \& Johansson-Stenman, O. (2008). Anonymity, reciprocity, and conformity: Evidence from voluntary contributions to a national park in Costa Rica. Journal of Public Economics, 92(5), 1047-1060.

Andreoni, J., \& Bernheim, B. D. (2009). Social image and the 50-50 norm: A theoretical and experimental analysis of audience effects. Econometrica, 77(5), 1607-1636.

Andreoni, J., \& Petrie, R. (2004). Public goods experiments without confidentiality: a glimpse into fundraising. Journal of public Economics, 88(7), 1605-1623.

Ariely, D., Bracha, A., \& Meier, S. (2009). Doing good or doing well? Image motivation and monetary incentives in behaving prosocially. The American Economic Review, 99(1), 544-555.

Austen-Smith, D., \& Fryer, R. G. (2005). An economic analysis of "acting white". The Quarterly Journal of Economics, 120(2), 551-583.

Bardsley, N., \& Sausgruber, R. (2005). Conformity and reciprocity in public good provision. Journal of Economic Psychology, 26(5), 664-681.

Becker, G. S. (1974). A Theory of Social Interactions. The Journal of Political Economy, 82(6), 10631093.

Bekkers, R., \& Wiepking, P. (2011). A Literature Review of Empirical Studies of Philanthropy Eight Mechanisms That Drive Charitable Giving. Nonprofit and Voluntary Sector Quarterly, 40(5), 924-973.

Bénabou, R., \& Tirole, J. (2006). Incentives and Prosocial Behavior. American Economic Review, 96(5), 1652-1678.

Bernheim, B. D. (1994). A theory of conformity. Journal of political Economy, 841-877.

Bohnet, I., \& Frey, B. S. (1999). The sound of silence in prisoner's dilemma and dictator games. Journal of economic behavior \& organization, 38(1), 43-57.

Bolton, G. E., Katok, E., \& Ockenfels, A. (2005). Cooperation among strangers with limited information about reputation. Journal of Public Economics, 89(8), 1457-1468.

Bond, R., \& Smith, P. B. (1996). Culture and conformity: A meta-analysis of studies using Asch's (1952b, 1956) line judgment task. Psychological bulletin,119(1), 111.

Carpenter, J., \& Myers, C. K. (2010). Why volunteer? Evidence on the role of altruism, image, and incentives. Journal of Public Economics, 94(11), 911-920.

Chen, Y., Harper, F. M., Konstan, J., \& Li, S. X. (2010). Social Comparisons and Contributions to Online Communities: A Field Experiment on MovieLens. American Economic Review, 100(4), 1358-98.

Cox, J. C., \& Deck, C. A. (2006). When are women more generous than men?. Economic Inquiry, 44(4), 587-598. 
Croson, R., \& Gneezy, U. (2009). Gender differences in preferences. Journal of Economic Literature, 448-474.

DellaVigna, S., List, J. A., Malmendier, U., \& Rao, G. (2013). The Importance of Being Marginal: Gender Differences in Generosity (No. w18748). National Bureau of Economic Research.

Dufwenberg, M., \& Muren, A. (2006). Generosity, anonymity, gender. Journal of Economic Behavior \& Organization, 61(1), 42-49.

Eagly, A. H. (1978). Sex differences in influenceability. Psychological Bulletin,85(1), 86.

Eagly, A. H., \& Carli, L. L. (1981). Sex of researchers and sex-typed communications as determinants of sex differences in influenceability: a meta-analysis of social influence studies. Psychological Bulletin, 90(1), 1 .

Eckel, C. C., \& Grossman, P. J. (2008). Differences in the economic decisions of men and women: Experimental evidence. Handbook of experimental economics results, 1, 509-519.

Engel, C. (2011). Dictator games: A meta study. Experimental Economics,14(4), 583-610.

Fehr, E., \& Gächter, S. (2000). Cooperation and punishment in public goods experiments. The American Economic Review, 90(4), 980-994.

Festinger, L. (1954). A theory of social comparison processes. Human relations, 7(2), 117-140.

Fischbacher, U., Gächter, S., \& Quercia, S. (2012). The behavioral validity of the strategy method in public good experiments. Journal of Economic Psychology.

Frey, B. S., \& Meier, S. (2004). Social comparisons and pro-social behavior: Testing" conditional cooperation" in a field experiment. The American Economic Review, 94(5), 1717-1722.

Gächter, S., \& Fehr, E. (1999). Collective action as a social exchange. Journal of Economic Behavior \& Organization, 39(4), 341-369.

Goeree, J. K., \& Yariv, L. (2007). Conformity in the Lab.

Hall, H. (2004). Gender differences in giving: Going, going, gone?. New Directions for Philanthropic Fundraising, 2004(43), 71-81.

Herrmann, B., Thöni, C., \& Gächter, S. (2008). Antisocial Punishment Across Societies. Science. 319(5868). 1362-1367.

Kanthak, K., \& Woon, J. (2012). Women Don't Run? Gender Differences in Candidate Entry.

King, A. J., Wilson, A. M., Wilshin, S. D., Lowe, J., Haddadi, H., Hailes, S., \& Morton, A. J. (2012).

Selfish-herd behaviour of sheep under threat. Current Biology, 22(14), R561-R562.

Kottasz, R. (2004). How should charitable organisations motivate young professionals to give philanthropically?. International journal of nonprofit and voluntary sector marketing, 9(1), 9-27. 
Krupka, E., \& Weber, R. (2008). Identifying social norms using coordination games: Why does dictator game sharing vary?.

Lacetera, N., \& Macis, M. (2010). Do all material incentives for pro-social activities backfire? The response to cash and non-cash incentives for blood donations. Journal of Economic Psychology, 31(4), 738-748.

Linardi, S., \& McConnell, M. A. (2008). Volunteering and image concerns. Working Paper \#1282, Humanities and Social Sciences, California Institute of Technology

Linardi, S., \& McConnell, M. A. (2011). No excuses for good behavior: Volunteering and the social environment. Journal of Public Economics, 95(5), 445-454.

Meier, S. (2005). Conditions under which women behave less/more pro-socially than men. Unpublished manuscript.

Mellström, C., \& Johannesson, M. (2008). Crowding out in blood donation: was Titmuss right?. Journal of the European Economic Association, 6(4), 845-863.

Niederle, M., \& Vesterlund, L. (2007). Do women shy away from competition? Do men compete too much?. The Quarterly Journal of Economics, 122(3), 1067-1101.

Noussair, C., \& Tucker, S. (2007). Public observability of decisions and voluntary contributions in a multiperiod context. Public Finance Review, 35(2), 176-198.

Pan, X. S., \& Houser, D. (2011). Competition for trophies triggers male generosity. PloS one, 6(4), e18050.

Parsons, P. H. (2004). Women's philanthropy: Motivations for giving (Doctoral dissertation, University of Alabama).

Peacey, M. W., \& Sanders, M. (2012). Masked Heroes: endogenous anonymity in charitable giving.

Rege, M., \& Telle, K. (2004). The impact of social approval and framing on cooperation in public good situations. Journal of public Economics, 88(7), 1625-1644.

Reinstein, D., \& Riener, G. (2012). Reputation and influence in charitable giving: An experiment. Theory and decision, 72(2), 221-243.

Salmon, T. C., \& Serra, D. (2013). Does Social Judgment Diminish Rule Breaking?

Croson, R., \& Shang, J. Y. (2008). The impact of downward social information on contribution decisions. Experimental Economics, 11(3), 221-233.

Shang, J., \& Croson, R. (2009). A field experiment in charitable contribution: The impact of social information on the voluntary provision of public goods. The Economic Journal, 119(540), 1422-1439.

Shi, L. (2011). Social Image Concern and the Crowd-out Effect of Extrinsic Rewards: Evidence from a Survey on Blood Donation.

Smith, S., Windmeijer, F., \& Wright, E. (2012). Peer effects in charitable giving: Evidence from the (running) field. 
Soetevent, A. R. (2005). Anonymity in giving in a natural context-a field experiment in 30 churches. Journal of Public Economics, 89(11), 2301-2323.

Taylor, M. A., \& Kaminski, A. R. (1997). Women as philanthropists: leading the transformation of fundraising. International Journal of Nonprofit and Voluntary Sector Marketing, 2(2), 107-113.

Wedekind, C., \& Braithwaite, V. A. (2002). The long-term benefits of human generosity in indirect reciprocity. Current Biology, 12(12), 1012-1015.

Zetland, D., \& Della Giusta, M. (2011). Focal points, gender norms and reciprocation in public good games. 


\section{Appendix A}

Table A1: Determinants of conditional contributions (OLS)

\begin{tabular}{|c|c|c|c|c|c|c|}
\hline VARIABLES & $\begin{array}{l}(1) \\
\text { All }\end{array}$ & $\begin{array}{l}(2) \\
\text { All }\end{array}$ & $\begin{array}{l}\text { (3) } \\
\text { All }\end{array}$ & $\begin{array}{c}(4) \\
\text { Drop } \\
\text { unlikely } \\
\text { scenarios }\end{array}$ & $\begin{array}{c}\text { (5) } \\
\text { Drop } \\
\text { unlikely } \\
\text { scenarios }\end{array}$ & $\begin{array}{c}\text { (6) } \\
\text { Drop } \\
\text { unlikely } \\
\text { scenarios } \\
\end{array}$ \\
\hline Vis. & $\begin{array}{c}0.631 \\
(0.515)\end{array}$ & $\begin{array}{r}-0.0803 \\
(0.554)\end{array}$ & $\begin{array}{l}-0.0803 \\
(0.556)\end{array}$ & $\begin{array}{c}0.629 \\
(0.567)\end{array}$ & $\begin{array}{l}-0.144 \\
(0.590)\end{array}$ & $\begin{array}{l}-0.146 \\
(0.588)\end{array}$ \\
\hline Vis. X Group mean & & $\begin{array}{l}0.142 * * * \\
(0.0415)\end{array}$ & $\begin{array}{c}0.142 * * * \\
(0.0417)\end{array}$ & & $\begin{array}{l}0.180 * \\
(0.102)\end{array}$ & $\begin{array}{l}0.181 * \\
(0.104)\end{array}$ \\
\hline Group mean & $\begin{array}{c}0.0607 * * * \\
(0.0216)\end{array}$ & $\begin{array}{l}-0.0105 \\
(0.0241)\end{array}$ & & $\begin{array}{c}0.393 * * * \\
(0.0517)\end{array}$ & $\begin{array}{c}0.305 * * * \\
(0.0730)\end{array}$ & \\
\hline Constant & $\begin{array}{c}2.706 * * * \\
(0.391)\end{array}$ & $\begin{array}{c}3.062 * * * \\
(0.390)\end{array}$ & $\begin{array}{c}3.010 * * * \\
(0.381)\end{array}$ & $\begin{array}{c}1.820 * * * \\
(0.417)\end{array}$ & $\begin{array}{c}2.204 * * * \\
(0.406)\end{array}$ & $\begin{array}{c}3.515 * * * \\
(0.431)\end{array}$ \\
\hline Scenario FE's & & & $\mathrm{X}$ & & & $\mathrm{X}$ \\
\hline $\begin{array}{l}\text { Observations } \\
\text { R-squared }\end{array}$ & $\begin{array}{l}3,150 \\
0.011\end{array}$ & $\begin{array}{l}3,150 \\
0.014\end{array}$ & $\begin{array}{l}3,150 \\
0.015\end{array}$ & $\begin{array}{l}1,739 \\
0.094\end{array}$ & $\begin{array}{l}1,739 \\
0.099\end{array}$ & $\begin{array}{l}1,739 \\
0.109\end{array}$ \\
\hline
\end{tabular}

Models 4-6 drop "unlikely scenarios". These are observations for which a participant thinks the scenario in question will not occur because she has assigned a probability of zero to one or both of the hypothetical contributions of group members.

Standard errors in parentheses, clustered at individual-level.

$$
* * * \mathrm{p}<0.01, * * \mathrm{p}<0.05, * \mathrm{p}<0.1
$$


Table A2: Replicating Table 2 without unlikely scenarios

\begin{tabular}{|c|c|c|c|c|c|}
\hline VARIABLES & $\begin{aligned} &(1) \\
&<\text { Min. }\end{aligned}$ & $\begin{aligned} & (2) \\
= & \text { Min. }\end{aligned}$ & $\begin{array}{c}(3) \\
\text { Strictly } \\
\text { within } \\
\end{array}$ & $\begin{aligned} & (4) \\
= & \operatorname{Max} .\end{aligned}$ & $\begin{aligned} & (5) \\
> & \operatorname{Max} .\end{aligned}$ \\
\hline \multicolumn{6}{|c|}{ Panel A: Impact of vis. } \\
\hline Vis. & $\begin{array}{c}-0.136 * * \\
(0.0657)\end{array}$ & $\begin{array}{l}0.00500 \\
(0.0338)\end{array}$ & $\begin{array}{c}0.0919 \\
(0.0591)\end{array}$ & $\begin{array}{c}0.0558 \\
(0.0356)\end{array}$ & $\begin{array}{l}-0.0148 \\
(0.0578)\end{array}$ \\
\hline Constant & $\begin{array}{c}0.487 * * * \\
(0.0495)\end{array}$ & $\begin{array}{l}0.258 * * * \\
(0.0227)\end{array}$ & $\begin{array}{c}0.269 * * * \\
(0.0400)\end{array}$ & $\begin{array}{l}0.159 * * * \\
(0.0230)\end{array}$ & $\begin{array}{c}0.237 * * * \\
(0.0427)\end{array}$ \\
\hline $\begin{array}{l}\text { Observations } \\
\text { R-squared }\end{array}$ & $\begin{array}{l}1,214 \\
0.119\end{array}$ & $\begin{array}{l}1,115 \\
0.051\end{array}$ & $\begin{array}{c}653 \\
0.090\end{array}$ & $\begin{array}{l}1,115 \\
0.044\end{array}$ & $\begin{array}{l}1,439 \\
0.065\end{array}$ \\
\hline \multicolumn{6}{|c|}{ Panel B: Impact of vis. on marginal types } \\
\hline Vis. (Just Above) & $\begin{array}{c}0.0117 \\
(0.0773)\end{array}$ & $\begin{array}{c}0.0377 \\
(0.0621)\end{array}$ & $\begin{array}{c}0.0770 \\
(0.0722)\end{array}$ & $\begin{array}{l}0.241 * * \\
(0.0997)\end{array}$ & $\begin{array}{c}-0.314 * * * \\
(0.110)\end{array}$ \\
\hline Vis. (Just Below) & $\begin{array}{l}-0.0717 \\
(0.0697)\end{array}$ & $\begin{array}{c}0.0969 \\
(0.0805)\end{array}$ & $\begin{array}{l}-0.0916 \\
(0.0566)\end{array}$ & $\begin{array}{l}0.00347 \\
(0.0242)\end{array}$ & $\begin{array}{l}-0.0223 \\
(0.0202)\end{array}$ \\
\hline Constant & $\begin{array}{c}0.397 * * * \\
(0.0488)\end{array}$ & $\begin{array}{l}0.321 * * * \\
(0.0290)\end{array}$ & $\begin{array}{l}0.319 * * * \\
(0.0407)\end{array}$ & $\begin{array}{l}0.189 * * * \\
(0.0254)\end{array}$ & $\begin{array}{c}0.195 * * * \\
(0.0411)\end{array}$ \\
\hline $\begin{array}{l}\text { Observations } \\
\text { R-squared }\end{array}$ & $\begin{array}{l}1,214 \\
0.372\end{array}$ & $\begin{array}{l}1,115 \\
0.097\end{array}$ & $\begin{array}{c}653 \\
0.162\end{array}$ & $\begin{array}{l}1,115 \\
0.089\end{array}$ & $\begin{array}{l}1,439 \\
0.202\end{array}$ \\
\hline
\end{tabular}

Standard errors in parentheses, clustered at individual-level.

Scenario fixed effects are included.

$* * * \mathrm{p}<0.01, * * \mathrm{p}<0.05, * \mathrm{p}<0.1$ 
Table A3: Replicating Table 3 without unlikely scenarios

\begin{tabular}{|c|c|c|c|c|c|}
\hline VARIABLES & $\begin{array}{c}\quad(1) \\
<\text { Min. }\end{array}$ & $\begin{aligned} & (2) \\
= & \text { Min. }\end{aligned}$ & $\begin{array}{c}(3) \\
\text { Strictly } \\
\text { within }\end{array}$ & $\begin{aligned} & (4) \\
= & \text { Max. }\end{aligned}$ & $\begin{array}{c}\quad(5) \\
>\text { Max. }\end{array}$ \\
\hline \multicolumn{6}{|c|}{ Panel A: Impact of vis. conditional on familiarity } \\
\hline Vis. (Familiar) & $\begin{array}{c}-0.118 \\
(0.0965)\end{array}$ & $\begin{array}{c}0.0343 \\
(0.0570)\end{array}$ & $\begin{array}{l}0.0703 \\
(0.103)\end{array}$ & $\begin{array}{c}0.0703 \\
(0.0564)\end{array}$ & $\begin{array}{l}-0.0461 \\
(0.105)\end{array}$ \\
\hline Vis. (Unfamiliar) & $\begin{array}{c}-0.157^{*} \\
(0.0859)\end{array}$ & $\begin{array}{l}-0.0195 \\
(0.0412)\end{array}$ & $\begin{array}{c}0.108 \\
(0.0687)\end{array}$ & $\begin{array}{c}0.0499 \\
(0.0457)\end{array}$ & $\begin{array}{c}0.0177 \\
(0.0632)\end{array}$ \\
\hline $\begin{array}{l}\text { Observations } \\
\text { R-squared }\end{array}$ & $\begin{array}{l}1,214 \\
0.140\end{array}$ & $\begin{array}{l}1,115 \\
0.055\end{array}$ & $\begin{array}{c}653 \\
0.090\end{array}$ & $\begin{array}{l}1,115 \\
0.048\end{array}$ & $\begin{array}{l}1,439 \\
0.091\end{array}$ \\
\hline \multicolumn{6}{|c|}{ Panel A Impact of vis. conditional on gender } \\
\hline Vis. (Male) & $\begin{array}{c}-0.119 \\
(0.0957)\end{array}$ & $\begin{array}{c}0.0129 \\
(0.0513)\end{array}$ & $\begin{array}{l}-0.0642 \\
(0.0772)\end{array}$ & $\begin{array}{c}0.0889 * * \\
(0.0450)\end{array}$ & $\begin{array}{c}-0.0099 \\
(0.0767)\end{array}$ \\
\hline Vis. (Female) & $\begin{array}{l}-0.152 * \\
(0.0865)\end{array}$ & $\begin{array}{l}-0.00543 \\
(0.0422)\end{array}$ & $\begin{array}{c}0.234 * * * \\
(0.0769)\end{array}$ & $\begin{array}{c}0.0292 \\
(0.0524)\end{array}$ & $\begin{array}{c}-0.0158 \\
(0.0833)\end{array}$ \\
\hline Constant & $\begin{array}{c}0.557 * * * \\
(0.0613)\end{array}$ & $\begin{array}{c}0.289 * * * \\
(0.0307)\end{array}$ & $\begin{array}{c}0.289 * * * \\
(0.0548)\end{array}$ & $\begin{array}{c}0.118^{* * *} \\
(0.0240)\end{array}$ & $\begin{array}{c}0.200 * * * \\
(0.0463)\end{array}$ \\
\hline Observations & 1,214 & 1,115 & 653 & 1,115 & 1,439 \\
\hline R-squared & 0.142 & 0.057 & 0.131 & 0.049 & 0.071 \\
\hline
\end{tabular}

Standard errors in parentheses, clustered at individual-level.

Scenario fixed effects are included.

$* * * \mathrm{p}<0.01, * * \mathrm{p}<0.05, * \mathrm{p}<0.1$ 
Figure A1: Distributions of belief normalized contributions by familiarity with cause

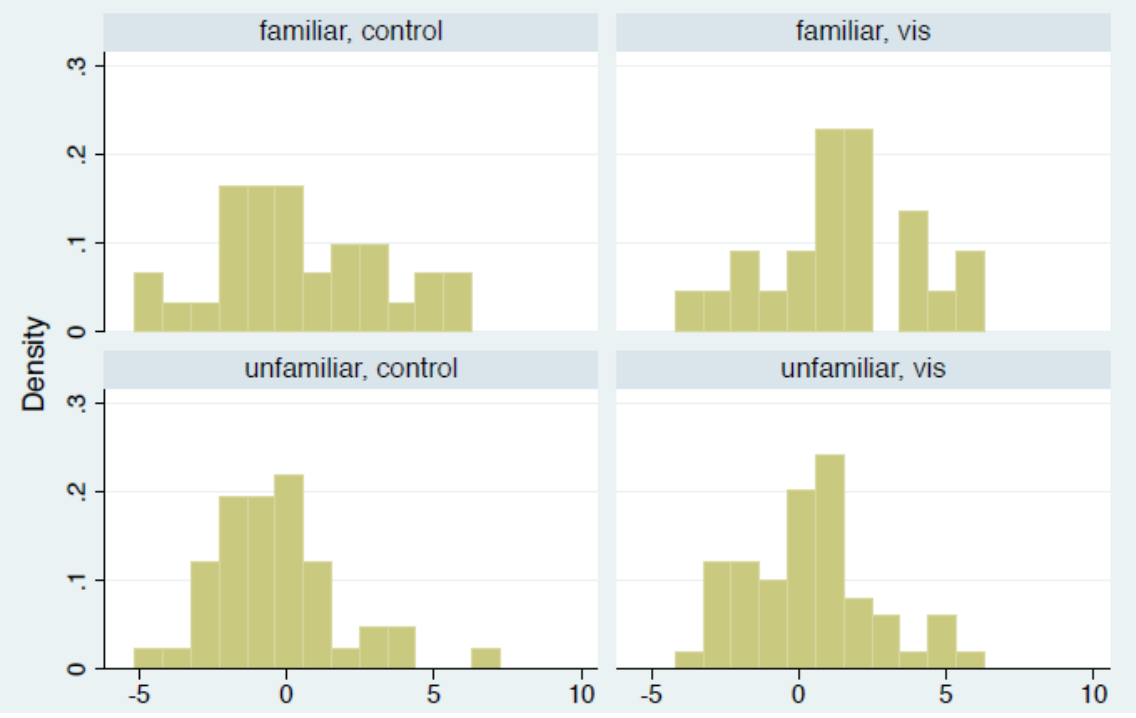

Table A4. Impact of "Names" revelation on likelihood of choosing modal contribution (Probit)

\begin{tabular}{lcc}
\hline VARIABLES & $\begin{array}{c}(1) \\
\operatorname{Pr}(\text { donation } \\
=\$ 1.80)\end{array}$ & $\begin{array}{c}(2) \\
\text { donation- } \\
\$ 1.80 \mid\end{array}$ \\
\hline \multirow{3}{*}{ Names (Male) } & -0.0975 & 0.648 \\
& $(0.224)$ & $(0.862)$ \\
Names (Female) & 0.377 & $-1.639^{*}$ \\
& $(0.248)$ & $(0.932)$ \\
Female & -0.211 & 0.260 \\
& $(0.211)$ & $(0.811)$ \\
1 other in booth & -0.0149 & 0.547 \\
& $(0.229)$ & $(1.034)$ \\
2 others in booth & 0.0400 & 0.360 \\
& $(0.227)$ & $(0.665)$ \\
3 others in booth & 0.177 & -0.689 \\
& $(0.238)$ & $(0.780)$ \\
4 others in booth & -0.0706 & 0.182 \\
& $(0.466)$ & $(0.583)$ \\
Constant & 0.420 & 1.689 \\
& $(0.252)$ & $(1.082)$ \\
Observations & & \\
R-squared & 51 & 51 \\
\hline
\end{tabular}

Column 1: Dependent variable is a dummy=1 if participant chooses donation $=\$ 1.80$.

Column 2: Dependent variable is absolute value of differences between donation and $\$ 1.80$.

Robust standard errors in parentheses

$$
* * * \mathrm{p}<0.01,{ }^{* *} \mathrm{p}<0.05,{ }^{*} \mathrm{p}<0.1
$$

